\title{
EL ENEMIGO INVISIBLE: LA SENSIBILIZACIÓN ANTE LAS ENFERMEDADES MENTALES A TRAVÉS DE LOS VIDEOJUEGOS
}

\author{
THE INVISIBLE ENEMY: RAISING AWARENESS OF MENTAL ILLNESS \\ THROUGH VIDEO GAMES
}

\author{
Guillermo Paredes Otero \\ Universidad de Sevilla. Sevilla / España \\ guillermoparedes87@gmail.com \\ https://orcid.org/0000-0002-9732-521X
}

Recibido/Received: 09/06/2020

Modificado/Modified: 26/07/2020

Aceptado/Accepted: 10/09/2020

\section{RESUMEN}

La estigmatización del individuo que padece una enfermedad mental es frecuente en la sociedad. Los medios de comunicación, incluidos los videojuegos, ofrecen una imagen de los pacientes mentales asociada a la violencia y la agresividad. Esto provoca unos prejuicios ejercidos desde los ámbitos familiares, educativos y profesionales que no ayudan a la comprensión real de trastornos como la depresión, la esquizofrenia o la ansiedad. En este contexto, los videojuegos serios o serious games ofrecen una representación alternativa desde los que mostrar una imagen de estas enfermedades más cercana a la realidad, buscando al mismo tiempo sensibilizar y la empatía del usuario. A través del análisis narrativo realizado a tres videojuegos -The Town of Light, Hellblade: Senua's Sacrifice y Celeste- con esta investigación se pretende averiguar qué herramientas se emplean en el ocio interactivo para concienciar sobre un problema social que afecta a millones de personas en la actualidad.

\section{PALABRAS CLAVE}

Análisis narrativo; enfermedades mentales; medios de comunicación; serious games; videojuegos.

\section{SUMARIO}

1. Introducción. 2. La estigmatización del enfermo mental desde los medios de comunicación. 3. La representación de las enfermedades mentales en los videojuegos. 4. Metodología. 5. Resultados. 5.1 The Town of Light. 5.2 Hellblade: Senua's Sacrifice. 5.3 Celeste. 6. Conclusiones. Bibliografia.

\begin{abstract}
Stigmatization of the individual suffering from a mental illness is frequent in society. The media, including video games, offer an image of mental patients associated with violence and aggressiveness. This causes prejudices exerted from the family, educational and professional spheres that do not help the real understanding of disorders such as depression, schizophrenia or anxiety. In this context, serious games offer an alternative representation from which to show an image of these diseases closer to reality, while seeking to sensitize and empathize the user. Through the narrative analysis carried out on three video games -The Town of Light, Hellblade: Senua's Sacrifice and Celeste- the aim of this research is to find out what tools are used in interactive entertainment to raise awareness about a social problem that affects millions of people in the present.
\end{abstract}




\section{KEYWORDS}

Narrative analysis; Mental illness; Mass media; Serious games; Video games.

\section{CONTENTS}

1. Introduction. 2. The stigmatization of the mentally ill from the media. 3. The representation of mental illness in video games. 4. Methodology. 5. Results. 5.1 The Town of Light. 5.2 Hellblade: Senua's Sacrifice. 5.3 Celeste. 6. Conclusions. References.

\section{INTRODUCCIÓN}

El ocio interactivo en la actualidad ha trascendido la barrera del entretenimiento con los llamados, serious games, término abordado por Abt (1970) para destacar el propósito educativo de los juegos de mesa y los juegos de cartas, más allá de su uso exclusivamente para la diversión. Gracias a la ludificación de la sociedad (Muriel y Crawford, 2018), los videojuegos se emplean en escenarios tan diversos como el educativo, el empresarial o el sanitario, entre otros, dando lugar nuevos roles y géneros. Los videojuegos permiten contar sucesos actuales e informativos a través de los Newsgames (Bogost, et al. 2010), ser usados como herramienta publicitaria o Advergames (Selva, 2009), mejorar los resultados en la salud de los pacientes, la formación de los profesionales y educar en materia de salud con los Serious Games for Health (Quintana y García, 2017), así como la transmisión de valores y concienciación ante problemas sociales.

En materia de sensibilización no existe un único término para definir a los serious games que cumplen con esta función. Bogost (2007) los atribuye como Persuasive Games mientras que para Morales (2015) son Social Committed Games. Paredes-Otero por su parte califica como Games for Social Change aquellos "videojuegos que, mientras enseñan valores sociales y cívicos, buscan la sensibilización de los ciudadanos ante problemas de carácter social" (Paredes-Otero, 2018: 308). Al margen del término que se emplee, estos videojuegos tienen en común concienciar sobre las temáticas que abordan y consideradas como problemas sociales, tales como la guerra, el racismo, la violencia de género, la homofobia, la crisis de refugiados $\mathrm{y}$, como veremos a lo largo de esta investigación, las enfermedades mentales.

Según la Organización Mundial de Salud, los casos de trastornos mentales continúan aumentando, provocando efectos no solo en la salud de las personas sino consecuencias en relación a derechos humanos. Según cifras a nivel mundial, la depresión es la enfermedad mental más frecuente, sufrida por 300 millones de pacientes, con síntomas que pueden derivar desde la tristeza y la falta de apetito hasta trastornos del sueño e incluso el suicidio. El trastorno afectivo bipolar afecta en torno a 60 millones de personas, mientras que psicosis como la esquizofrenia se ha contabilizado en alrededor de 21 millones de pacientes. En el caso de la demencia, 47,5 millones de personas padecen algún tipo de deterioro de la función cognitiva y su efecto en capacidades como la memoria, el pensamiento, la orientación, la comprensión o el lenguaje (OMS, 2019).

Siendo las enfermedades mentales un problema social como demuestran las cifras de afectados, consideramos pertinente investigarlas desde el punto de vista de cómo éstas se representan a través de un fenómeno cultural con relevancia en ámbitos tan diversos de la sociedad como son los videojuegos.

\section{LA ESTIGMATIZACIÓN DEL ENFERMO MENTAL DESDE LOS MEDIOS DE}




\section{COMUNICACIÓN}

Las enfermos mentales, al igual que otros grupos sociales como las mujeres, los inmigrantes o los colectivos LGTB, han sido estigmatizados desde hace siglos y ligados a estereotipos, entendiendo éstos como la "imagen compartida que existe en un grupo social relativa a las características atribuidas a los miembros de otro grupo social” (Cano, 1993: 269). En función de la enfermedad mental, los estereotipos varían. La esquizofrenia va asociada a la violencia, la agresividad y la impredictibilidad; el trastorno obsesivo compulsivo se relaciona con la infantilización o la incapacidad; mientras que la depresión o la ansiedad es entendida como debilidad (Cazzaniga y Suso, 2015). Magallares (2011) recurre a Putman para destacar cómo estas creencias populares derivan en una serie de prejuicios y acciones discriminatorias que el enfermo mental debe sufrir en diferentes contextos de su vida. En el ámbito laboral, el paciente mental se ve sujeto a situaciones de falta de oportunidades de empleo, actitud condescendiente por parte de los empleados, carentes de responsabilidades y muy controlados. En las relaciones personales son percibidos como una carga, teniendo excesiva presión en su recuperación y culpabilizándolos de la enfermedad. Cazzaniga y Suso (2015) añaden en esta esfera las acciones de sobreprotección, actitudes paternalistas, compasivas y sentimientos de vergüenza. Además, los familiares son reproductores del estigma derivado.

No obstante, la esfera en la que vamos a profundizar es el ámbito de los medios de comunicación. La revisión de estudios previos, en estos campos consultados, coinciden en que los medios de comunicación vinculan los trastornos mentales con la agresividad y la violencia como se verá a continuación. En términos generales, Dickerson et al. (2002) pusieron de manifiesto que la información, publicada por los medios, cubren actos violentos cometidos por personas con alguna enfermedad mental, teniendo connotaciones hirientes y ofensivas. En la prensa escrita, Nairn et al. (2001) concluyeron que los temas predominantes eran los referentes a derechos humanos y el riesgo de peligro y amenaza de los pacientes, reproduciéndose caracterizaciones de las enfermedades mentales incompletas y genéricas. Wahl (2000) destacó el hecho de que, frente a la esquizofrenia, otras enfermedades como el trastorno obsesivo compulsivo no tienen tanta repercusión en las revistas. Por su parte, el análisis sobre programas emitidos en televisión y realizado por Wilson et al. (1999) reflejaron que los personajes con alguna enfermedad mental carecían de comprensión y aparecían perdidos, impredecibles, vulnerables y peligrosos hasta para ellos mismos.

Algunos autores destacan que detrás de estos mensajes hay una intencionalidad más allá de la puramente informativa. Construcciones elaboradas deliberadamente que, independientemente de que contradigan los resultados de las investigaciones, son emitidas en base a criterios comerciales (María, 2010). El ámbito donde se publica la información así como el posicionamiento ideológico del medio son otros factores determinantes (Bueno y Mestre, 2005), dándose casos en los que las fuentes no se comunican claramente a causa de la necesidad del periodista de crear un relato que provoque interés, sin que quede reflejada la forma que los psiquiatras tienen de exponer los casos, en aras de difundir los trastornos mentales de forma negativa (Nairn, 1999), recurriendo al sensacionalismo para atraer al receptor (Cazzaniga y Suso, 2015).

Otros medios de comunicación de masas perpetúan la emisión de estos estereotipos. En el caso del cine, la locura no es recreada de manera objetiva ni comprensible para el público, se sirven de ella "para atrapar a los espectadores en tramas eficaces y rentables que estimulan el morbo o la fascinación que la enfermedad mental provoca en las personas comunes y corrientes" (De la Peña, 2009: 15). Los mensajes con estereotipos también están presentes en los medios de comunicación infantiles. Wahl (2009) destacó que los enfermos mentales 
tienden a ser poco atractivos en su apariencia, ridiculizados por otros personajes, y siendo la respuesta correcta el internamiento y aislamiento en vez de la empatía y el tratamiento.

Partiendo de la base de considerar el ocio interactivo como una obra comunicativa que tiene un contenido discursivo (Pérez-Latorre, 2012) capaz de llegar a un público cada vez más numeroso -existiendo a día de hoy más de 2,5 billones de usuarios en todo el mundo (Newzoo, 2019)-, entendemos el videojuego como un medio de comunicación masivo desde el cual investigar qué representación ofrece de las enfermedades mentales y las similitudes y diferencias que tiene con otros medios.

\section{LA REPRESENTACIÓN DE LAS ENFERMEDADES MENTALES EN LOS VIDEOJUEGOS}

Actualmente hay dos vías de mostrar las enfermedades mentales a través del ocio interactivo. Una forma clásica donde los personajes hacen gala de los prejuicios y estigmas ligados a los pacientes mentales y una línea de representación alternativa donde, a través de serious games, se abordan dichas dolencias desde un punto de vista realista e informan y sensibilizan sobre el tema. Atendiendo a la manera frecuente, el género por excelencia donde se usan los trastornos psíquicos como eje central de la trama es el de los juegos de terror en los cuales pueden verse unos patrones comunes. El personaje principal suele sufrir una amnesia que le impide recordar momentos concretos de su vida y de gran importancia para la trama del juego o directamente no sabe por qué está en un lugar y momento determinados.

La falta de memoria es una de las señas de identidad de la saga Silent Hill. Silent Hill 2 (Konami, 2001) comienza cuando el protagonista, James Sutherland, recibe una carta de su esposa Mary citándolo en la localidad de Silent Hill. El problema es que ella está muerta a causa de una enfermedad. Una vez llegado al enclave, tras conocer a una mujer llamada María e idéntica a su difunta esposa y enfrentarse a diversas criaturas, averiguamos que fue el propio protagonista quien le practicó eutanasia a su esposa mientras estaba ingresada en el hospital. Esto le provocó un trauma que le hizo volver a Silent Hill, un lugar especial para ellos, siendo los enemigos del juego una representación de su mente torturada (Lifante, 2018).

En el caso de Layers of Fear (Bloober Team, 2016), el trastorno obsesivo compulsivo se presenta desde el punto de vista del terror psicológico con un pintor que siente la imperiosa necesidad de pintar su obra maestra hasta el punto de caer en el alcoholismo, provocar el suicidio de su mujer y abandonar a su hija. Todo el juego tiene lugar en la mente del pintor mientras recoge materiales necesarios para su obra provenientes de su esposa. Tras multitud de fenómenos paranormales y escenarios que cambian a su antojo, al final termina el cuadro, el cual no lo convence y lo guarda en una habitación con decenas de cuadros idénticos, solo para volver a ponerse a pintar ante un nuevo lienzo como si de un ciclo sin fin se tratase.

El género del terror no es el único en presentar enfermedades y pacientes mentales. Until Dawn (Supermassive Games, 2015) es una aventura narrativa basado en la toma de decisiones donde encontramos a Josh, un joven tratado de depresión y esquizofrenia, que, después de ver cómo sus dos hermanas mueren a causa de una broma por unos amigos, decide corresponderles haciéndose pasar por asesino para aterrorizarles. El enfermo se presenta como una persona sin empatía y desconectado de la realidad. Por su parte, dentro del género de acción y aventuras encontramos la saga de Alice Liddell -American McGee's Alice (Rogue Entertainment, 2000) y Alice: Madness Returns (Spicy Horse, 2011)-, la revisión del cuento Alicia en El País de las Maravillas. Tras presenciar la muerte de sus padres y hermana en un incendio en su casa, Alicia queda dañada psicológicamente e internada en un asilo mental. El objetivo del juego consiste 
en devolver la paz al País de las Maravillas, desfigurado a causa del estado mental de Alicia, teniendo que acabar con los personajes clásicos del cuento original con una amplia variedad de armas, empezando por un enorme cuchillo.

La representación de las instituciones mentales sigue esta fórmula de ligar la enfermedad con la violencia y la agresividad sumándole un nuevo factor: la experimentación con los pacientes. En Manhunt 2 (Rockstar, 2007) la brutalidad hizo que algunas partes fueran censuradas e incluso prohibido su lanzamiento en Reino Unido (González, 2007). Este título de Rockstar vuelve a presentar a un protagonista amnésico, Daniel Lamb, que no recuerda nada de su pasado y cómo ha llegado a despertar en el manicomio. Junto a otro enfermo mental, Leo Kasper, debe recordar su historia mientras hace frente al resto de personajes que hay en el sanatorio. El punto que no hace sino resaltar los estigmas de la enfermedad mental es la forma de hacerlo: empleando desde armas de fuego hasta, palas e, incluso un bolígrafo, en mecánicas denominadas ejecuciones, donde se eliminan a los enemigos a través de decapitaciones y amputaciones.

El juego Outlast (Red Barrels, 2013), por su parte, pone al usuario en la piel de un periodista quien, después de recibir un correo anónimo, decide ir a investigar las actividades de un manicomio y los experimentos ilegales que tienen lugar ahí. El objetivo es averiguar qué ocurre realmente mientras nos ocultamos de los pacientes, quienes están en libertad y no dudan en perseguir y acabar con el protagonista a la mínima oportunidad.

En esta línea, The Evil Within (Bethesda, 2014) presenta a un detective que debe investigar la escena de un asesinato múltiple en un hospital mental. La escena inicial con enfermeras, pacientes y doctores mutilados indica lo que se convierte en una constante a lo largo del juego siendo los enemigos principales criaturas de pesadilla. También se juega con la idea de que el protagonista es un enfermo mental y paciente de la institución. Su estado inicial es el de una persona que sufre los efectos del trauma que le ha causado la muerte de su mujer e hija.

Por otro lado y desde el punto de vista de los serious games, Night in the Woods (Infinite Fall, 2017) gira en torno a Mae Borowsky, una estudiante universitaria que regresa a su casa después de abandonar sus estudios. A lo largo del juego conocemos los motivos que llevaron a Mae a tomar esta decisión y, lo que parecía una historia de reencuentro entre ella y sus familiares y amigos así como el día a día en una localidad en decadencia por una crisis económica, resulta ser un título sobre la enfermedad mental, concretamente sobre el trastorno disociativo.

Por su parte, El viaje de Elisa (Fundación Orange y Autismo Burgos, 2017) contó en su desarrollo con la participación de la Federación de Autismo de Castilla y León y la Fundación Orange. Prueba de que cada vez son más las empresas que se sirven del ocio interactivo para poder transmitir sus mensajes y difundir su trabajo. En esta ocasión, el usuario tiene ante sí un juego donde la única salvación de una sociedad perteneciente a un planeta de otra galaxia es un adolescente de la Tierra con Síndrome de Asperger. A través de cinco minijuegos se sensibiliza y educa sobre cómo es la vida cotidiana del paciente y los síntomas.

Siguiendo con la depresión, en Depresión Quest (Zoe Quinn, Patrick Lindsley e Isaac Schankler, 2013) el usuario es cuestionado sobre diversas situaciones de la vida cotidiana y, en función de las elecciones que tome, puede salir o agravar su estado depresivo. Emporium (Tom Kitchen, 2017), por su parte, trata sobre esta enfermedad mental llevada a su última consecuencia, el suicidio. El juego comienza con un hombre muerto enfrente de un edificio, teniendo el jugador que descubrir a lo largo de los recuerdos de esta persona, los motivos que le han llevado a acabar así. Finalmente, Forgotten (Mutiny Games, 2018) permite conocer cómo es la vida diaria de una enferma de Alzheimer. 


\section{METODOLOGÍA}

En esta investigación nos hemos centrado en esta segunda vía, teniendo como objetivo analizar cómo es la representación alternativa que ofrecen los videojuegos, considerados serious games, con las enfermedades mentales como temática principal y las herramientas que emplean tanto para abordarlas como para sensibilizar sobre ellas.

El enfoque que se emplea en este trabajo es el del videojuego como un fenómeno narrativo, argumento defendido por autores como Anyó (2016) o Zimmerman (2004). Asimismo, Jenkins (2004) entiende este formato como un entorno narrativo relacionado con las narraciones transmediáticas. Sin embargo, también entendemos el ocio interactivo como simulación (Frasca, 2003; Grodal, 2003). Este último define el proceso de estar ante un videojuego como una forma de ofrecer "experiencias personalizadas que se basan en el juego (es decir, procesos de aprendizaje repetitivos placenteros), respaldados por emociones que cambian con el tiempo" (Grodal, 2003: 153). Frasca, por su parte, argumenta que, mientras los medios tradicionales se basan en la representación, los videojuegos tienen un enfoque alternativo conocido como simulación (2003).

La falta de consenso, con dos formas de entender el videojuego (narración o simulación), queda de manifiesto a la hora que tienen los autores de analizar el videojuego, teniendo cada uno su propio modelo de análisis. Desde la Narratología, Anyó (2016) apuesta por tres categorías de análisis: la estructura y el conjunto de reglas del juego; el mundo que se muestra; y la jugabilidad, compuesta por el conjunto de acciones, motivaciones y estrategias que el jugador puede realizar. Por su parte, Frasca (2003) enfoca el análisis desde el campo de la Ludología usando un método de análisis compuesto por cuatro niveles: el primero centrado en la representación y los acontecimientos, incluyendo las características de objetos, personajes, escenarios, condiciones y escenas. Un segundo nivel compuesto por las reglas de manipulación o aquello que el jugador puede hacer. El tercer nivel presta atención a las reglas de objetivos, aquello que el usuario debe hacer para ganar. Y un cuarto y último nivel, dedicado a las metarreglas, la libertad que tiene el jugador de poder cambiar las reglas, de modificar alguno de los tres niveles anteriores.

El acercamiento entre diferentes teorías lo encontramos en casos como Pérez-Latorre (2012), partidario de aplicar un enfoque transdisciplinar con una base compartida de Semiótica y Ludología, y la realización de análisis semioludológico, tres modelos de análisis para entender el discurso del videojuego: el modelo lúdico, el modelo narrativo y el modelo enunciativo.

Por lo tanto, y teniendo en cuenta los diversos métodos de estudio de ocio interactivo tanto narrativos como de simulación, para esta investigación se ha apostado por la aplicación de un análisis lúdico-narrativo compuesto por cinco categorías: el personaje principal (1) o nexo de unión entre el usuario y el mundo de ficción del videojuego así como principal elemento de inmersión en los acontecimientos de la partida (Tato, 2017). Todo lo que le ocurra en el juego lo padece el jugador, creándose la sensación de empatía. También nos hemos fijado en la enfermedad mental (2); el problema o trastorno mental que tiene el personaje principal, los síntomas y cómo estos se representan en la pantalla. Con las mecánicas de juego (3) se ha querido saber la forma que tiene el usuario de interactuar con los diferentes elementos que componen el juego -enfrentándose a enemigos, tomando decisiones, movimientos de destreza y habilidad, etc. (Pérez-Latorre, 2012)- y qué relación tiene con la enfermedad mental y sus síntomas. En cuanto a los prejuicios (4); la culpa, la agresividad, la violencia o la falta de oportunidades de empleo están ligadas a los enfermos mentales. La idea es comprobar si 
también tienen lugar en los juegos analizados. Finalmente, con las formas de sensibilización (5) se ha prestado atención a las estrategias empleadas para conseguir la implicación y empatía del usuario respecto a la enfermedad mental. Paredes-Otero (2018) destaca que usar perfiles de personajes débiles y el uso de mensajes directamente dirigidos al jugador son herramientas comunes en los serious games para concienciar.

Estas categorías de análisis se han aplicado sobre tres videojuegos concretos: The Town of Light (LKA, 2016), Hellblade: Senua's Sacrifice (Ninja Theory, 2017) y Celeste (Matt Makes Games, 2018). La elección de estos juegos responde a varios criterios de selección. En primer lugar, los tres pertenecen a la actual generación de videojuegos (las próximas plataformas PlayStation 5 y Xbox Series X- no se esperan hasta mediados de noviembre de 2020), por lo tanto, la imagen que se da sobre las enfermedades mentales es la representación actual dentro del ocio interactivo. Además, no son juegos exclusivos de una determinada consola, han sido lanzados a todas las plataformas actuales de entretenimiento interactivo (PlayStation 4, Xbox One, Nintendo Switch y PC) por lo que el mensaje que lanzan va destinado a todos los usuarios del mercado de videojuegos, independientemente del soporte. Por otro lado, el género al que pertenecen es diferente. Hellblade: Senua's Sacrifice es un juego de acción, Celeste es un plataformas, mientras que The Town of Light es un walking simulator. Esto nos permite comprobar qué patrones en común hay en estos juegos y si existe alguna diferencia entre ellos dependiendo de su género. Por último, la muestra seleccionada corresponde a juegos considerados por la prensa especializada como una representación alternativa de los trastornos mentales (Matas, 2020).

\section{RESULTADOS}

Los resultados se exponen usando cada videojuego como una unidad independiente para, a continuación, en las conclusiones, sacar aspectos comunes sobre las categorías analizadas.

\subsection{The Town of Light}

Este juego del estudio LKA y lanzado al mercado en 2016 es un thriller psicológico en primera persona y ambientado en el Hospital Psiquiátrico de Volterra, un asilo mental fundado a finales del siglo XIX en la región italiana de Toscana y en funcionamiento hasta su cierre en los años 70. El objetivo de los desarrolladores, a la hora de crear este juego, puede conocerse a través de un vídeo incluido como extra llamado 'Renée y la salud mental' y consiste en "abordar un tema tan controvertido como el de las enfermedades e instituciones mentales con la sensibilidad que se merece". El usuario tiene ante sí lo que ocurría realmente en esa época dentro de una institución mental. Esto es gracias a la investigación previa realizada por los desarrolladores quienes no solamente pasearon por los pasillos y habitaciones de dicho enclave para reproducirlo en el juego. Las entrevistas realizadas a psiquiatras, psicólogos y personas que trabajaron allí, disponibles en el diario de desarrollo añadido a The Town of Light y titulado 'Investigación y Volterra', cumplen con la finalidad de "mostrar la enfermedad de un personaje muy creíble en un entorno muy creíble". El juego, por lo tanto, le otorga al enclave la misma importancia que a la protagonista del juego siendo la enfermedad mental el nexo de unión entre ambos.

La historia de The Town of Light traslada al jugador al año 2016 para recorrer el Hospital Psiquiátrico de Volterra en un estado de absoluto abandono desde la perspectiva de Renée, una paciente que, en los años cuarenta, estuvo allí ingresada. Aun siendo un personaje ficticio, la protagonista y su historia son la personificación de todos los testimonios e investigación 
documental realizada sobre los cientos de pacientes que fueron ingresaron ahí con unos estigmas que aún perduran. La historia de Renée es la de una joven de 16 años enferma de esquizofrenia que es internada por su madre, después de protagonizar situaciones como emborracharse e incluso prostituirse. Conforme avanza el juego, se descubre el origen de estas acciones y la decisión del familiar de internarla. La historia la cuenta la propia Renée conforme va andando por las diferentes estancias, intercalándose escenas del presente con el hospital en ruinas con flashbacks en blanco y negro de cuando ella era una paciente.

Los síntomas relacionados con la esquizofrenia se presentan de dos formas: a partir de informes que el personal sanitario hizo de ella mientras era paciente y a través de la manifestación de los propios síntomas. Atendiendo a los informes, Renée es una enferma mental que durante un tiempo se creyó que padecía tuberculosis. De ahí que tardara meses en ser ingresada y diagnosticada de su dolencia real. Con dificultad para alimentarse y episodios de psicosis y ansiedad. Asimismo sufre alucinaciones, desorientación y confusión a la vez que oye gritos en su cabeza. Presentando también episodios de violencia y tendencias suicidas.

Todos estos síntomas se materializan en algún momento siendo las alucinaciones el más frecuente. Sobre todo cuando se trata del personaje de Amara, de quien Renée habla constantemente haciendo que el jugador sienta la misma confusión que la propia protagonista cuando los datos que va averiguando no se corresponde con los recuerdos. En un principio, Amara se presenta como otra joven interna con la que tuvo una relación sentimental y siendo apartadas al descubrirse su romance. Sin embargo, la realidad fue otra, siendo una mujer adulta y casada con la que nunca tuvo contacto más allá de una sonrisa, ingresada durante periodos muy cortos y que acabó muriendo de tuberculosis. Es a raíz de ese fugaz momento lo que lleva a Renée y su trastorno mental a construir toda una relación amorosa.

Independientemente de ser imaginaria, se pone de manifiesto la importancia del apoyo de terceras personas hacia los enfermos mentales. Renée describe a Amara como su "única esperanza en ese infierno. Estaba cayendo entre los condenados, pero esa mujer y su sonrisa me mantuvieron con vida".

También hay situaciones de alteración de la realidad como las paredes ondulando o los pasillos por los que se mueve cambiando de perspectiva. La violencia y los intentos de suicidio también suceden y se justifican al producirse primero, cuando una vez le rechazan el darle de alta, apuñalándose con unas tijeras, $\mathrm{y}$, segundo, al intentar ahorcarse debido a que su madre ha muerto y no tiene nadie que la cuide, por lo que deberá quedarse ahí siempre. Esta segunda negativa la interpreta ella como "una sentencia de cadena perpetua".

El juego también representa estigmas ligados a los enfermos mentales. En el ámbito social, se sabe a través del diario que escribe Renée que ella empezó a padecer esquizofrenia entre los seis y los siete años cuando perdió el sentido y al volver en sí le costaba reconocer objetos, personas e incluso palabras. Entre los siete y diez años siguió teniendo estos episodios siendo señalada en el colegio. Esto se representa en una escena años posteriores cuando ve a todos los niños de una clase mirándola fijamente y riéndose de ella.

El desconocimiento junto a la vergüenza por las situaciones que protagonizaba su hija hicieron que su madre optara por internarla. Los desarrolladores explican que este momento responde al hecho de que los pacientes mentales se veían como algo inhumano, no como una persona y la sociedad escondía lo que consideraba vergonzoso. Como indica el estudio LKA en el vídeo incluido en el juego como extra 'Eliminando el estigma', se desestigmatiza al enfermo, buscando "rechazar la vergüenza, creer que los trastornos son un problema que afrontar y resolver".

Estas reacciones sociales y familiares derivan en un sentimiento de autoculpa en Renée cuando la situación se hace insostenible. En un momento, ella puede escribir una carta a su 
madre con expresiones tipo 'Ahora me portaré bien, seguro que ahora las cosas irán mejor' y que demuestran la desesperación que siente: 'Solo quiero morir, espero no volver a despertarme por la mañana'.

Desde el punto de vista sanitario, la discriminación hacia el paciente queda patente con el trato al que enfermeras y celadores someten a Renée. Representados como seres carentes de rostro o serios y con ojos brillantes, le arrancaban la ropa, le daban duchas de agua fría, la obligaban a ponerse camisas de fuerza y era atada a la cama, e incluso violada. Con este episodio de abuso sexual se ponen de manifiesto tanto las vejaciones que se producían en los centros mentales como la poca credibilidad que tenían los enfermos. Por el hecho de tener un problema mental, no se toma en serio el testimonio de Renée, calificándolo como una alucinación en un informe. De no ser por una carta escrita por una enfermera en un amago de denunciar el caso que finalmente no envió sumado al hecho de que aparece un aborto en el informe de Renée, el usuario podría pensar que este hecho nunca tuvo lugar.

Respecto a la representación histórica que se hace del Hospital Psiquiátrico de Volterra, éste es un lugar en donde se deja de vivir. "Me dijeron que me llevarían a un lugar donde el miedo se iría, donde me pondría mejor" pero fue todo lo contrario: "Sola con mis pesadillas. Ya no hubo más miedo, ¡hubo locura! Y cuando estás loco dejas de existir". La historia no hace sino recalcar que, comparada con el resto de pacientes, ella no debería de estar ahí. Queda plasmado en una escena en la que están todas las enfermas en sus camas cada una gritando o desnudas y Renée acostada con cara de terror, como si no perteneciera a ese lugar.

El privarla de cualquier contacto con el exterior, la violación por un miembro del personal y despojarla de sus objetos personales hacen empeorar su estado. Conforme avanza la historia vemos que los tratamientos aumentaron en brutalidad, pasando de terapias de electrochoque a una lobotomía transorbital. Esta última la convierte en un ser prácticamente inanimado. $\mathrm{Su}$ estado lo explica en los últimos segundos del juego uno de los doctores destacando que, con 23 años, "le falta vitalidad. Solo sigue igual su inteligencia y la tristeza de sus ojos. Probablemente no mejore. Su vida ha sido desechada. Nadie hizo nada para tratar de impedirlo". Estas palabras tienen lugar mientras se ve a Renée con la mirada perdida, sentada sola en un banco y con la ropa manchada.

Finalmente, la concienciación sobre el tema la encontramos principalmente en que la historia la cuenta Renée en primera persona, es ella misma la narradora de su vida y de los hechos que están apareciendo en pantalla. Al jugador, también se le hace partícipe, como si ella supiera que está ahí. Esto tiene lugar cuando se dirige al jugador con expresiones tipo 'Seguro que ella está por aquí' o 'Vamos, sigamos buscando'. Todas las vejaciones que sufre desde su infancia hasta la madurez y que se pueden vivir como si fueran hacia uno mismo, su indefensión, tener la misma confusión que la protagonista al no saber qué fue real y qué producto de su imaginación, así como la recreación del lugar, no hacen sino producir un sentimiento de empatía con Renée y su situación mental.

\subsection{Hellblade: Senua's Sacrifice}

El videojuego creado por Ninja Theory se aleja de la imagen clásica de los enfermos mentales ofrecida por el ocio interactivo desde la fase de desarrollo del propio juego. Al margen de la búsqueda de documentación sobre el contexto histórico en el que se desarrolla la historia, costumbres y mitología nórdica, sus creadores buscaban ofrecer una perspectiva renovada de la enfermedad. "Los videojuegos tienen la capacidad de sumergirte en su mundo durante horas, asumiendo un papel de un personaje que es distinto de ti, experimentando su punto de vista" (Ninja Theory, 2018).

Para ello, los síntomas de enfermedad mental que padece la protagonista del juego son la 
reproducción de los testimonios obtenidos de primera mano de asociaciones, pacientes y expertos en este campo de estudio (Ninja Theory, 2016). Gracias a esa colaboración, el usuario puede "profundizar en su psique -de la protagonista del juego-, sus recuerdos, sus emociones y representar físicamente el mundo a su alrededor" (Ninja Theory, 2015) tal y como ella lo ve y lo siente.

"Las enfermedades mentales, como la psicosis, siguen siendo un tema tabú y pocas veces se les ha dado el reconocimiento en todo un siglo de cine, por no hablar del nuevo medio de los videojuegos. Cuando sí aparecen, a menudo se confunde la psicosis con la psicopatía, que se caracteriza por la ausencia de empatía" (Ninja Theory, 2018).

Hellblade: Senua's Sacrifice (2017) es un juego de acción que traslada al jugador a finales del siglo VIII a las Islas Orcadas (Escocia) para presentar a la guerrera picta, Senua, quien padece una psicosis grave, en su misión de llegar al Hellheim (el reino de la muerte en la mitología nórdica) y rescatar el alma de su amado Dilion, asesinado y sacrificado durante un ataque vikingo, de las manos de la diosa Hela.

Todo el viaje es una construcción de la mente de Senua donde su enfermedad mental es el pilar del juego y sus recuerdos con Dilion y el resto de personajes de su pasado van construyendo el presente. Uno de los aspectos de la psicosis es ver patrones y asociaciones y encontrarles un significado (Ninja Theory, 2017). Hay un momento en el que Senua pierde su espada y debe encontrar otra pero que está fragmentada. Sus pedazos están en diferentes zonas y debe hacer los llamados trabajos de Odín, un símil creado por su mente en base a los trabajos como guerrero que tenía su amado.

Por su parte, los enemigos ante los que Senua hace frente responden a la mitología y tradición oral de los nórdicos, a los cuales nunca llega a hacer frente ya que simplemente son producto de su mente. Los únicos rivales que realmente aparecen durante el viaje son los vikingos contra los que lucha. Pero éstos se presentan distorsionados, deformados y con los rostros ocultos a causa del miedo que les tiene Senua.

La jugabilidad de Hellblade: Senua's Sacrifice proviene de las entrevistas realizadas a enfermos mentales y es una representación de sus síntomas (Ninja Theory, 2018). En ocasiones el paciente ve todo en pedazos como una fotografía que está rasgada. Esto lo sufre Senua cuando el escenario se presenta como un vidrio fragmentado. Ver los colores más brillantes se manifiesta sobre todo a la hora de resaltar objetos importantes para la resolución de puzles. También hay ocasiones en las que el mundo se presenta como un caleidoscopio o las paredes tienen ondulaciones, como si se derritieran. Asimismo, el que la mente les haga ver en blanco y negro o contemplar personas colgadas en el techo tienen cabida en el juego cuando Senua sufre ataques psicóticos, en uno de los cuales las víctimas de los vikingos aparecen colgadas y ella tiene que caminar entre ellas. En cuanto a colores y objetos cotidianos, éstos tienen más significado y forman rompecabezas. En Hellblade, hay zonas bloqueadas que solamente se abren si encuentras una runa concreta. Éstas se forman con objetos del escenario como vigas de edificios, ramas de árboles o adornos colgados, dependiendo de la perspectiva y posición desde las que se las mire.

El síntoma más habitual representado son las voces que oye Senua en su cabeza. "Oír voces es una experiencia normalmente asociada a la enfermedad mental" y son parte de la vida cotidiana de estas personas (Ninja Theory, 2016). Estas voces las ha escuchado siempre, de hecho su madre también las oía, aunque fue cuando presenció a su amado crucificado entre dos árboles cuando aparecieron nuevas voces. Con esto Ninja Theory hace hincapié en que, si bien es cierto que un trauma puede agravar la dolencia mental, éste no tiene por qué ser siempre el origen de la misma. En ocasiones puede provenir de los genes personales.

En momentos puntuales, estas voces son una forma de concienciación sobre la enfermedad 
mental al romper la cuarta pared y dirigirse directamente al usuario para hacerle partícipe de la trama con expresiones como "Tiene miedo, ¿no lo tendrías tú?” o "¿Por qué no nos acompañas? Quizás tu tengas un papel en esta historia". De hecho, Senua llega a mirar fijamente a la cámara como si supera que el usuario está ahí y es una de las voces.

En cuanto a los estigmas, el desconocimiento que existe en la sociedad actual ante estos problemas, como causa de los prejuicios que se tienen, se expone ligando la psicosis a la superstición, calificándola como un castigo de los dioses. El juego está lleno de mensajes para concienciar al usuario sobre la propia enfermedad así como de las actitudes de la sociedad y la creación de prejuicios. "La oscuridad cuando habla lo cambia todo: convierte el hogar en tierra extraña y a las personas amadas en desconocidos. El exilio cobra sentido cuando te das cuenta de que, en realidad, nunca habías estado en casa". La falta de entendimiento deriva en miedo ante quienes son diferentes. "Temen lo que no pueden ver. Como los niños que temen a la oscuridad. Por eso se inventan cuentos, para llenar el vacío. No por eso son ciertos".

La principal representación de la incomprensión ante los trastornos mentales está en la figura del padre de Senua, Zynbel, un personaje religioso que personifica todos los estigmas que la sociedad atribuye a la psicosis. A su mujer Galena, también enferma mental, la quemó viva por considerarla maldita. A la propia Senua la tuvo años encerrada sin salir de casa y aplicándole rituales. Este periodo de cautiverio hizo mella en la protagonista cuando, años más tarde, durante el viaje sobre el que gira el juego, tiene que avanzar por una mazmorra, creada por su mente, señal del periodo que estuvo prisionera.

El desconocimiento sumado a la presión social hacen que la propia Senua tome esos prejuicios como ciertos. Puede verse cuando piensa que es culpable de ser la causante de la plaga (cuando en realidad se trataba de una enfermedad corriente) que asola su clan, estigma que le han puesto quienes la rodean, hasta el punto de provocar que Senua tenga que exiliarse al bosque sola. El ser la primera en oler la podredumbre mientras estaba con otros miembros del clan sumado a la fama de maldita son las causas de este aislamiento voluntario.

Finalmente, Hellblade: Senua's Sacrifice tiene lecciones para aplicar fuera del videojuego. En primer lugar, la importancia que tiene el apoyo de otras personas para los enfermos mentales. En el caso de Senua es Dilion. "Antes de conocerle, las cosas no le iban bien. Era solo una chica, pero no como las demás. Apenas podía desenvolverse, rara vez salía de su casa. Ya se aseguraba de ello Zynbel, su padre... Así era su mundo, yermo y solitario". Cuando le conoció, "las tinieblas se despejaron" teniendo en ella el efecto de un "rayo de esperanza". Este efecto se extendió más allá de la muerte de Dilion. A lo largo de la aventura, Senua tiene diversos momentos de crisis a causa de su enfermedad siendo en todos ellos el recuerdo y las palabras de ánimo que le daba la forma de superarlos.

Por otro lado, Senua es presentada como una gran guerrera que incluso llamaba la atención de quienes la veían manejar la espada. El significado de esto es que, el tener una enfermedad mental no es motivo para no poder destacar en algo. Solamente hay que tener la oportunidad para demostrarlo.

\subsection{Celeste}

Celeste es un juego de plataformas desarrollado por Matt Makes Games y lanzado al mercado en 2018. La historia trata sobre Madeline, una joven que sufre de ansiedad y tiene el objetivo de escalar la Montaña Celeste, una hazaña con la que busca demostrarse a sí misma de ser capaz de completar un reto con éxito.

Cada etapa del ascenso supone una lección, tanto para ella como para el propio usuario, incluidas las mecánicas. Celeste se caracteriza por la facilidad que existe a la hora de morir y tener que repetir la pantalla. Un mal salto, no saber calcular el llegar de una plataforma a otra, entre decenas de 
situaciones, conducen a la eliminación del personaje. Sin embargo, en este juego el fracaso no se ve como negativo sino como algo sobre lo que aprender, obtener un conocimiento.

El ascenso por la montaña permite conocer el trasfondo de Madeline. Su obcecación por llegar a la cima, siendo cualquier otro resultado un fracaso, es comparable con el pesimismo y negatividad que presenta en algunos momentos, de sentirse incapaz de conseguir algo en su vida. Escalar Celeste es darle un rumbo y un propósito a su vida para dejar de sentirse inútil ya que ella experimenta la sensación de estar siempre "en medio del mar. Sin nada a su alrededor. Es claustrofóbico".

Todos estos sentimientos negativos y su problema mental se personifican, gracias al misterioso poder de la montaña, en la figura de Badeline, idéntica a la protagonista pero con el pelo morado. Durante todo el juego persigue a Madeline e intenta que abandone, diciendo que es imposible y que no puede lograrlo. En un primer momento, la joven pretende desprenderse de su parte negativa, consiguiendo únicamente enfadar a Badeline y ser arrojada hacia la base de la montaña teniendo que iniciar el ascenso de nuevo. El mensaje que se extrae de esto es que no se puede luchar contra lo que uno es, hay que aceptarse así mismo con sus virtudes y sus defectos. En el momento que Madeline comprende que Badeline es parte de ella, escalar la montaña es más fácil, materializándose en nuevas mecánicas como realizar más saltos en el aire.

Los personajes secundarios son importantes para tratar la ansiedad en Celeste. Por un lado, el señor Oshiro es el fantasma del encargado de un hotel cuya existencia, al igual que en vida, es la de hacer sentir bien a todo aquel que pase por dicho enclave hasta el punto de volverse una obsesión y conseguir precisamente lo contrario: espantar a todos los posibles huéspedes. En cambio, Theo es otro escalador que acompaña de Madeline en determinados momentos de la historia. Su presencia resalta la importancia de contar con ayuda externa y lo trascendental que es saber que alguien cree en nosotros. Las conversaciones con Theo permiten a la protagonista abrirse y contar realmente cómo se siente y hacer más llevadera la enfermedad. En un punto de la aventura, mientras ambos están en un teleférico, éste se para y quedan suspendidos en el aire. Esta situación hace que Madeline tenga un ataque de pánico, del cual gracias a Theo consigue salir cuando le enseña una forma de relajación.

Por último, también queda patente que una enfermedad mental no debe ser vista como un impedimento para conseguir objetivos propuestos sino como una salvedad más a la que hacer frente. Madeline logra llegar a la cima en una actividad que exige tanto esfuerzo físico como mental como es la escalada. Además consigue incluso salvarle la vida a Theo de quedar atrapado en la montaña a pesar de su condición.

\section{CONCLUSIONES}

Esta investigación ha demostrado cómo, al margen de una vía clásica de videojuegos que reflejan las enfermedades mentales de una forma llena de estereotipos propios de las prácticas de los medios de comunicación donde se representa al enfermo como alguien violento y agresivo, existe una forma alternativa centrada en la sensibilización ante este problema social.

Los videojuegos analizados tienen como protagonistas a mujeres jóvenes, aunque hemos visto cómo en otros serious games centrados en enfermedades mentales los personajes principales son varones. Independientemente del género, su representación es de una persona común que tiene una enfermedad de la que no se puede curar. Las enfermedades que padecen los protagonistas son representadas de una manera real, alejándose de la espectacularidad y el morbo. Un realismo que se demuestra desde el proceso de desarrollo de los juegos, en los casos 
de Hellblade: Senua's Sacrifice y The Town of Light, con la búsqueda de documentación y entrevistas a pacientes con trastornos mentales. Al final el usuario puede vivir en la pantalla la enfermedad tal y como es gracias a testimonios de primera mano.

Aunque el objetivo de los personajes sean otros (recordar, escalar una montaña o salvar a un ser querido) el objetivo que se le plantea al usuario es el mismo: conocer los síntomas de las diferentes enfermedades mentales, cómo es la vida de quienes las padecen y empatizar con su situación. Gracias a la interactividad propia de los videojuegos, esta finalidad es más fácil de alcanzar, pudiendo oír las voces propias de la esquizofrenia, superar ataques de ansiedad o ver el mundo distorsionado como si el usuario fuera quien tiene dicha enfermedad. En este punto, las mecánicas o formas con las que el usuario interactúa con el juego como la exploración son fundamentales.

La estigmatización que sufren los enfermos mentales es representada desde un punto de vista de denuncia ante la misma, teniendo cabida las discriminaciones y abusos en los ámbitos familiares, profesionales, sociales e incluso sanitarios. La presencia de estas situaciones en el juego sirven para hacer ver que, aunque estemos ante un producto de ficción, los personajes y su historia están basados en hechos reales.

Los juegos analizados incluyen mensajes educativos como datos sobre tratamientos mentales como en el caso de The Town of Light y lecciones, siendo la más frecuente la importancia para el paciente de tener a alguien que le ayude, con quien desahogarse o, simplemente, le haga ver que no está solo, y el aceptarse tal y como se es. Por último, la implicación del usuario en la acción, más allá de la interactividad, con acciones como el personaje hablando con el propio jugador, hace que este último empatice aún más con dicha problemática social.

\section{BIBLIOGRAFÍA}

Abt, C. (1970). Serious Games. Nueva York: Viking Press.

Anyó, L. (2016). El jugador implicado. Videojuegos y narraciones. Barcelona: Laertes.

Bogost, I. (2007). Persuasive Games. The expressive power of videogames. Londres: Massachusetts Institute of Technology.

Bogost, I., Ferrari, S y Schweizer, B. (2010). Newsgames. Journalism at Play. Cambridge: The MIT Press.

Bueno, J.R. y Mestre, F.J. (2005). Prensa y representaciones sociales de la enfermedad mental. Intervención Psicosocial, vol. 14(2), 131-159.

Cano, J.I. (1993). Los estereotipos sociales. El proceso de perpetuación a través de la memoria selectiva (tesis doctoral). Madrid: Universidad Complutense de Madrid, accesible en http://webs.ucm.es/BUCM/tesis/19911996/S/1/S1001901.pdf [consulta 18/06/2020]

Cazzaniga, J. y Suso, A. (2015). Salud mental e inclusión social. Situación actual y recomendaciones contra el estigma. RED2RED CONSULTUTORES, en: https://consaludmental.org/publicaciones/Salud-Mental-inclusion-social-estigma.pdf $\quad$ [consulta $18 / 06 / 2020]$

De la Peña, F. (2009). Las imágenes de la locura en el cine como representaciones culturales. Cuicuilco, $45,11-25$.

Dickerson, F.B., Sommerville, J., Origoni, A.E., Ringel, N.B. y Parente, F. (2002). Experiences of stigma among patients with schizophrenia. Schizophrenia Bulletin, 28(1), 143-55. DOI: https://doi.org/10.1093/oxfordjournals.schbul.a006917

Frasca, G. (2003). Simulation versus narrative: Introduction to ludology. En Wolf, M. J. P.; Perron, B. (Eds.), The video game theory reader. New York: Routledge, pp. 221-236.

González, D. (2007). "El videojuego 'Manhunt 2' prohibido en el Reino Unido por ser demasiado brutal”. 
20 Minutos, en https://www.20minutos.es/videojuegos/noticia/videojuego-manhunt-censurado249565/0/ [consulta 9/6/2020].

Grodal, T. (2003). Stories for eye, ear, and muscles: Video games, media, and embodied experiences. En Wolf, M. J. P.; Perron, B. (eds.), The video game theory reader. New York: Routledge, pp. 126-156.

Jenkins, H. (2004). Game design as narrative architecture. En Wardrip-Fruin, N.; Harrigan, P. (eds.), First person. New media as story, performance and game. Cambridge: The MIT press, pp. 117-130.

Lifante, S. (2018). La ciudad doliente. Bienvenidos a Silent Hill. Sevilla: Héroes de Papel.

Magallares Sanjuan, A. (2011). El estigma de los trastornos mentales: discriminación y exclusión social. Quaderns de Psicologia, 13(2), 7-17, DOI: https://doi.org/10.5565/rev/qpsicologia.816

María, H. (2010). Enfermedad Mental y Violencia en los Medios de Comunicación. ¿Una asociación ilícita? Quaderns de Psicología, vol. 12(1), 95-107, DOI: https://doi.org/10.5565/rev/qpsicologia.738

Matas, F.G. (2020). "Los juegos que hablan de los problemas y trastornos mentales". Vandal, en https://vandal.elespanol.com/reportaje/los-juegos-que-hablan-de-los-problemas-y-trastornosmentales [consulta 5/6/2020]

Morales Corral, E. (2015). Serious Games. Diseño de videojuegos con una agenda educativa y social. Barcelona: Editorial UOC.

Muriel, D. y Crawford, G. (2018). Video Games as culture. Considering the Role and Importance of Video Games in Contemporary Society. Londres: Routledge.

Nairn, R., Coverdale, J. y Claasen, D. (2001). From source material to news story in New Zealand print media: a prospective study of the stigmatizing processes in depicting mental illness. Australian and New Zealand Journal of Psychiatry, 35, 654-659. DOI: https://doi.org/10.1080/0004867010060515

Newzoo (2019). Global Games Market Report 2019. Newzoo, en: https://newzoo.com/products/reports/global-games-market-report/ [consulta 18/06/2020]

Ninja Theory (Dir.) (10/6/2015). "Hellblade Development Diary 12: The Mind of Senua", [Vídeo], Ninja Theory https://www.youtube.com/watch?v=zS6wHzwUDI4 [consulta 7/6/2020]

Ninja Theory (Dir.) (25/11/2016). "Hellblade: Senua's Sacrifice Development Diary 24: Hearing Voices", [Vídeo], Ninja Theory https://www.youtube.com/watch?v=LQQ2Jm2dgXk [consulta 7/6/2020]

Ninja Theory (Dir.) (3/3/2017). "Hellblade: Senua's Sacrifice | Dev Diary 26 | Myths \& Madness", [Vídeo], Ninja Theory https://www.youtube.com/watch? $\mathrm{v}=\mathrm{cPq}-7 \mathrm{Ai} 3 \mathrm{r}$ Q [consulta 7/6/2020]

Ninja Theory (Dir.) (10/10/2018). "Hellblade: Senua's Psychosis | Mental Health Feature", [Vídeo], Ninja Theory https://www.youtube.com/watch? $\mathrm{v}=31 \mathrm{PbCTS} 4 \mathrm{Sq} 4 \& \mathrm{t}=16 \mathrm{~s}$ [consulta 7/6/2020]

OMS (2019). "Trastornos mentales". Organización Mundial de la Salud, en https://www.who.int/es/news-room/fact-sheets/detail/mental-disorders [consulta 21/06/2020]

Paredes-Otero, G. (2018). Los serious games como herramientas educo-in- formativas para el diseño de la conciencia social. En Torres-Toukoumidis, A.; Romero-Rodríguez, L.M. (Eds.). Gamificación en Iberoamérica. Experiencias desde la comunicación y la educación. Quito: Editorial Universitaria Abya-Yala, pp. 303-330.

Pérez-Latorre, O (2012). El Lenguaje Videolúdico. Análisis de la significación del videojuego. Barcelona: Laertes.

Quintana, Y. y García, O. (2017). Serious Games for Health. Mejora tu salud jugando. Barcelona: Gedisa Editorial.

Selva, D. (2009). El videojuego como herramienta publicitaria: una aproximación al concepto de advergaming. Comunicación, 7 (1), 141-166.

Tato, G. (2017). Análisis del personaje en el cine y en los videojuegos. Inmersión y empatía. Quaderns $d e$ Cine, 12, 105-117. DOI: https://dx.doi.org/10.14198/QdCINE.2017.12.09

Wahl, O.F. (2000). Obsessive-Compulsive Disorder in Popular Magazines. Community Mental Health Journal, vol.36, n³, 307-312, DOI: https://dx.doi.org/10.1023/A:1001913415961

Wahl, O.F. (2009) .Depictions of mental illnesses in children's media. Journal of Mental Health, 12 (3), 249-258. DOI: https://doi.org/10.1080/0963823031000118230

Wilson, C., Nairn, R., Coverdale, J. y Panapa, A. (1999). Mental illness depictions in prime-time drama: identifying the discursive resources. Australian and New Zealand Journal of Psychiatry, 33, 232 239. DOI: https://dx.doi.org/10.1046/j.1440-1614.1999.00543.x 
Zimmerman, E. (2004). Narrative, interactivity, play, and games: Four naughty concepts in need of discipline. En Wardrip-Fruin, N.; Harrigan, P. (Eds.) First person. New media as story, performance and game. Cambridge: The MIT Press, pp. 154-164.

\section{Breve currículo:}

\section{Guillermo Paredes Otero}

Doctorando del Programa de Doctorado Interuniversitario en Comunicación por parte de la Universidad de Sevilla en la línea de Periodismo. Graduado en Periodismo (CEADE) y Máster en Comunicación y Cultura en la Universidad de Sevilla, junto a los estudios postgrado de Máster en Periodismo Digital, en la Universidad de Alcalá de Henares, y Máster en Periodismo Deportivo, en la Escuela CES de Imagen y Sonido. Miembro de Ladecom (Laboratorio de estudios en comunicación). Experiencia en redacciones de diversos medios de comunicación como periodista y community manager. Mi línea de investigación está centrada en los videojuegos como fenómeno cultural y herramienta periodística. 